\title{
Reconstruction of the Tongue Defect after Excision of Cavernous Hemangioma with Rotational Advancement flap in A Child
}

Pavan Kumar Batchu', Ram Mohan S2, Shwetang Goswami ${ }^{3}$, Yashwanth Yadav ${ }^{4}$

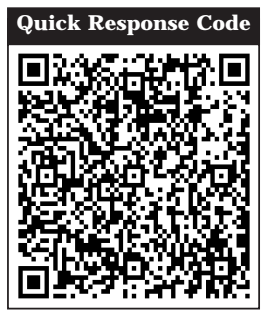

doi: $10.5866 / 2015.7 .10207$

IProfessor \& HOD

${ }^{2,3 \& 4}$ Senior Lecturer

Department of Oral \& Maxillofacial Surgery,

Kamineni Institute of Dental Sciences, India

\section{Article Info:}

Received: J uly 13, 2015

Review Completed: August 12, 2015

Accepted: September 10, 2015

Available Online: J uly, 2015 (www.nacd.in)

C NAD, 2015 - All rights reserved

\section{Email for correspondence:}

pavankumarbatchu@yahoo.co.in

\section{Introduction:}

The oral cavity, head and neck regions possess complex, rich and intricate blood vessels which might be a predisposing factor for a variety of vascular lesions. These lesions represent the most common growths in infancy and childhood, and may vary from small innocent birthmarks to large disfiguring tumours. Based on their clinical behaviour and the endothelial cell characteristics. ${ }^{1{ }^{1}}$ 2 these lesions have been recently categorized into two groups as vascular malformation or hemangiomas. It is agreed that vascular lesions

\begin{abstract}
:
Hemangiomas affecting the soft tissues of the oral cavity represent the most common growths in infancy and childhood. They are usually present at birth but become clinically obvious in late infancy or early childhood. Treating those lesions pose a challenge to the surgeon. Reconstruction of a medium-sized defect of the tongue remains a challenge if aesthetic and functional impairment is to be avoided. Most hemangiomas develop in children less than 6 years of age and commonly are seen on lips, tongue, palate and buccal mucosa. We present a case of cavernous hemangi oma of the tongue which was treated by circumferential excision and rotational advancement flap.
\end{abstract}

Key words: Hemangioma, Rotational advancement flap 
endothelial cells turnover, a number of mast cells during rapid growth phase, diminished cellularity with fibrous tissues and low mast cell counts during involution. ${ }^{5}$ The present paper discusses a case of tongue hemangioma treated with excision and rotational advancement flap.

\section{Case History:}

An 8-year-old boy was referred for evaluation of a growth that was present on the dorsum of right side of the tongue that had been clinically apparent for approximately 1 year. Patient reported that the area was easily traumatized by eating, with secondary swelling and occasional bleeding. The child had a normal medical history with no unusual findings in relation to the mother's pregnancy, labor, or delivery. His family history was noncontributory and on physical examination he appeared to be healthy and of normal size and weight. At the time of presentation, the lesion continued to be symptomatic. On physical examination of the oral cavity, there was a 4.5-cm red and purple vascular lesion that involved less than one half of the tongue. Oral examination demonstrated the lesion with enlarged papilla on dorsum of tongue and tongue tie present (Figure 1). After photographs were taken the written consent was obtained. The clinical end point was blanching upon pressure. The surface appeared to be smooth and hyperkeratotic with a gray hue that blanched slightly under pressure. The lesion was soft to palpation. The remainder of the oral examination was essentially normal. No positive cervical lymphadenopathy could be detected.

Ultrasound and Doppler imaging showed illdefined heterogenous lesion, largely hypoechoic, seen on left side of the tongue in sub mucosal region. The lesion was clinically diagnosed as a hemangioma, and the selected treatment was the excision of lesion and rotational advancement flap for closure of the defect. The signs of revascularization after finger pressure were determined and no pulsations were obtained from the lesion and the lesion was diagnosed as hemangioma.

Under General Anesthesia the surgery was performed. I nitially tongue tie was released. Tongue protruded to normal movement. 3-0 silk sutures were used to retract for better accessibility and exposure of lesion (Figure 2). By using monopolar electro cautery total excision of Iesion was done, lingual artery was identified and ligated (Figure 3 and 4). Using rotational flap i.e. anterior part of tongue of other side, the defect was approximated (Figure 5). Suturing was done by using 3-0 vicryl suture (Figure 6). Recovery was uneventful. Histopathologically the excisional biopsy diagnosed as cavernous hemangioma. Microscopically connective tissue stroma showed large dilated blood filled cavities lined by plump endothelial cells. Three months postoperatively patient was examined for tongue retrusion, protrusion and lateral movements and functional and aesthetic requirements were achieved (Figure 7).

\section{Discussion:}

The widespread belief that hemangiomas will completely disappear in the frist few years of life is misleading, as shown by Finn et al who reported that $80 \%$ of lesions that had not involuted by 6 years (and 38\% of lesions that had involuted at 6 years) left behind a residual cosmetic deformity. ${ }^{6}$ The psychosocial trauma of a visible lesion in a growing child, and the poor outcome of benign neglect, taken with the current availability of drugs, lasers, and other techniques to treat theselesions safely, should warrant a change in the philosophy of "benign neglect". 6-9

A useful approach to the management of hemangiomas can be based on the stage of the lesion (proliferative or involutive phase), type of lesion (supercial, deep, compound) and the management of residual deformity. ${ }^{10,11}$ I $n$ general, life-threatening and sight-threatening hemangiomas should be dealt with, regardless of the stage of the lesion. Active intervention should be considered in all disfiguring hemangiomas, but each case should be managed on its merits after careful discussion and counselling, to prevent potential psychosocial trauma and cosmetic deformity. ${ }^{10,12,13}$

\section{Table 1}

\section{Current classication of haemangioma and vascular malformations ${ }^{14}$}

\section{A. Hemangiomas}

Supercial (capillary haemangioma)

Deep (cavernous haemangioma)

Compound (capillary cavernous haemangioma) 


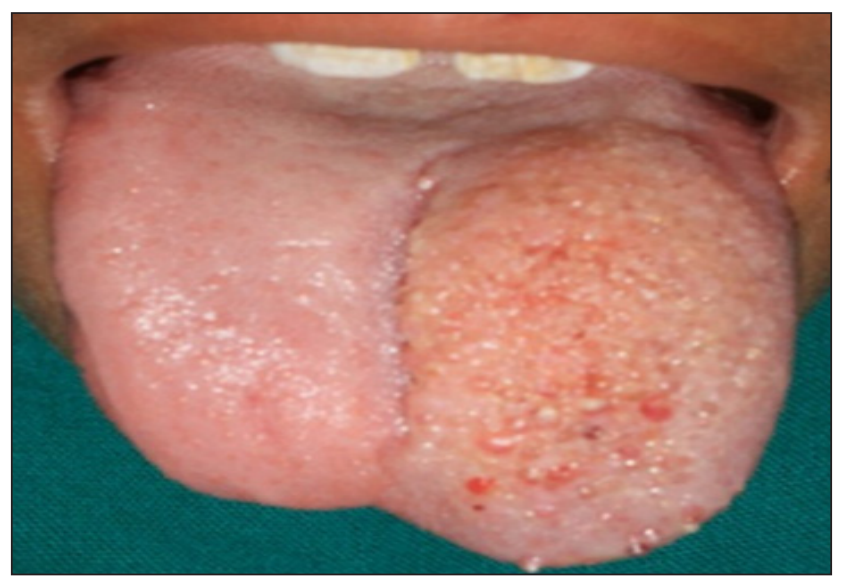

Figure 1: Clinically lesion is seen with enlarged papilla on dorsum of tongue.

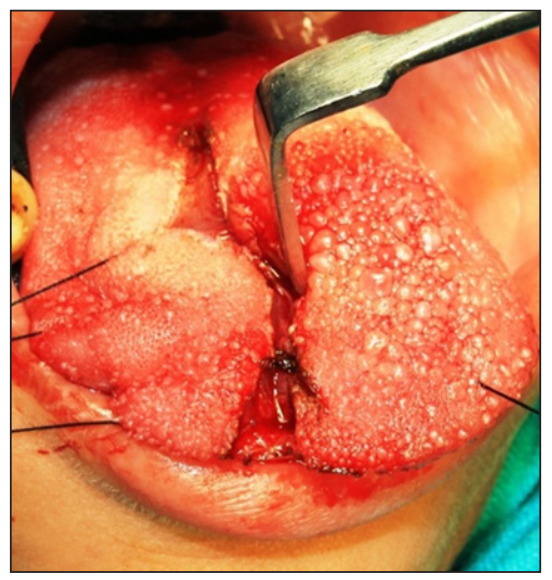

Figure 3: Lingual artery is identified and ligated.

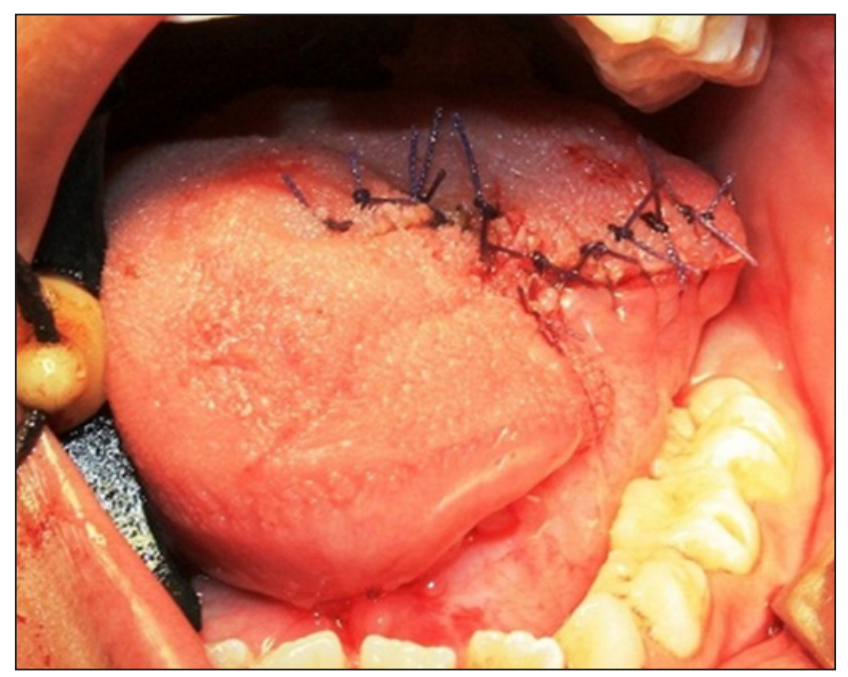

Figure 6: Suturing was done by using 3-0 vicryl suture. Three months postoperatively patient was examined for tongue retrusion, protrusion and lateral movements and functional and aesthetic requirements were achieved (Figure 7).

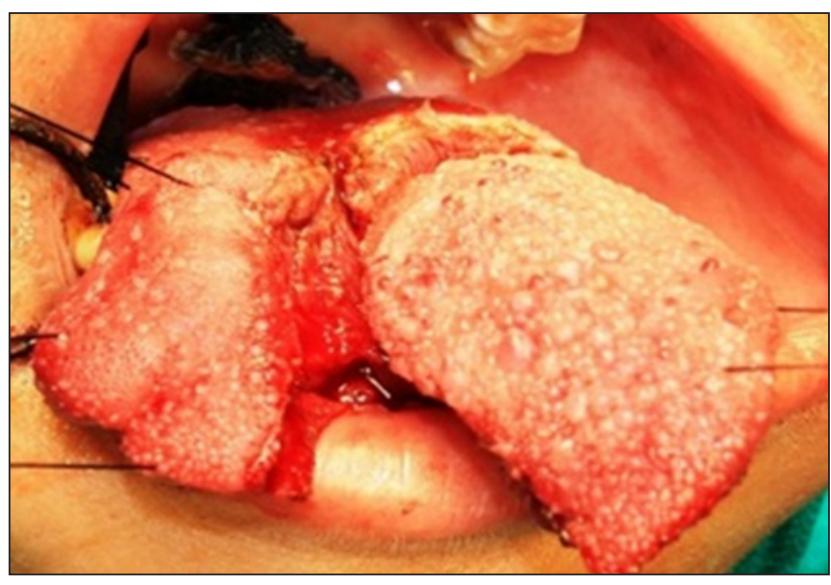

Figure 2: 3-0 silk sutures were used to retract for better accessibility and exposure of lesion.

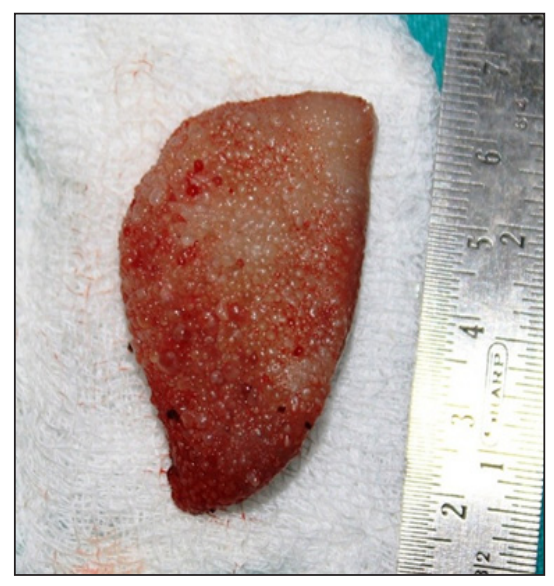

Figure 4: By using monopolar electro cautery total excision of lesion was done.

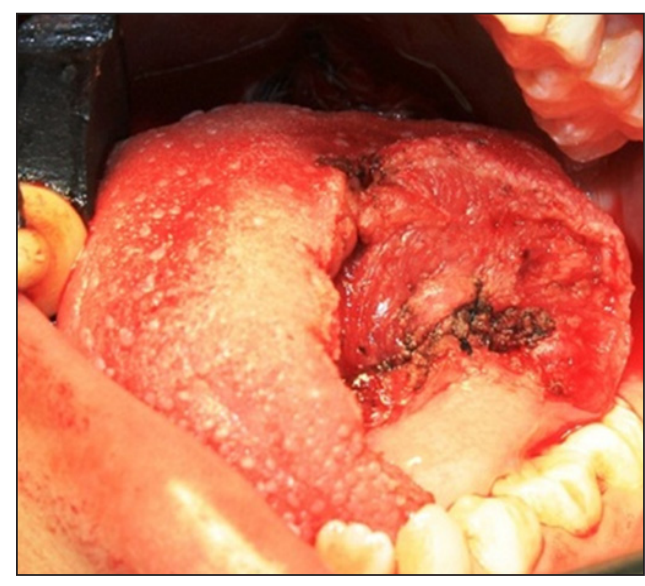

Figure 5: Using rotational flap i.e. anterior part of tongue of other side, the defect was approximated.

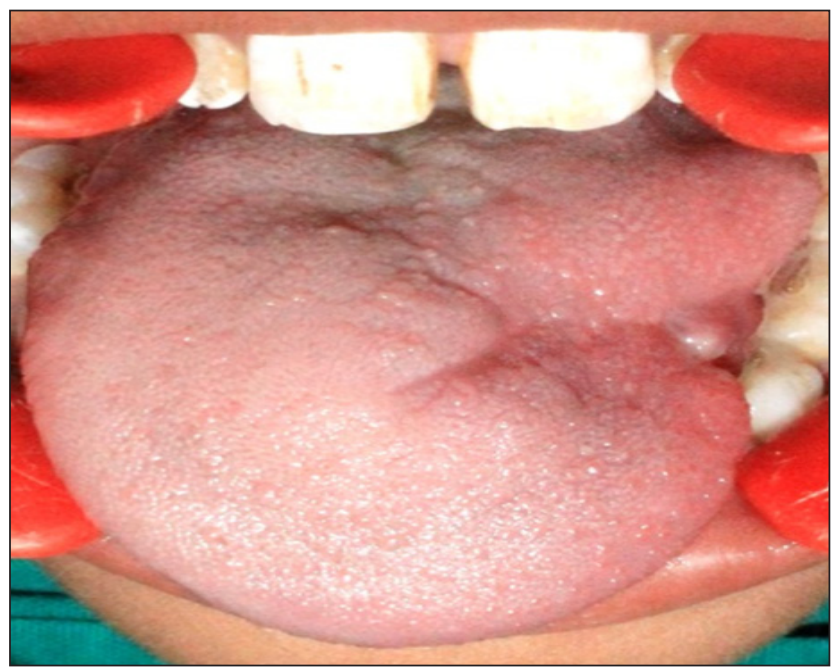

Figure 7: Three months postoperatively, patient was examined for tongue retrusion, protrusion and lateral movements and functional and aesthetic requirements were achieved. 


\section{B. Vascular malformations}

Simple lesions

\section{Low-flow Lesions}

Capillary malformation (capillary haemangioma, port-wine stain)

Venous malformation (cavernous haemangioma)

Lymphatic malformation (lymphangioma)

\section{High-flow Lesions}

Arterial malformation

\section{Combined lesions}

Arteriovenous malformations

Lymphovenous malformations

Other combinations

The diagnosis and the classification of the vascular malformations have a great importance on the treatment plan of the lesions. Mulliken and Glowacki proposed a terminology for classifying these lesions that is based on clinical and microscopic features. ${ }^{1}$ This system broadly classifies vascular lesions into hemangiomas and vascular malformations. The hemangioma is the true vascular tumor that results from a neoplastic overgrowth of normal vascular tissue. The hemangioma grows by endothelial proliferation. In distinction to hemangiomas, vascular malformations results from abnormal vascular or lymphatic vessel morphogenesis, not as the result of abnormal endothelial growth. Hemangiomas are usually present at birth and can be diagnosed by 1 year, whereas vascular mal formations are present at birth but often not diagnosed until second decade of life. The three stages in the life cycle of a hemangioma, each characterized by a unique assemblage of biologic markers and processes, are (1) the proliferating phase (0-1 year of age), (2) the involuting phase (1-5 years of age), and (3) the involuted phase ( $>5$ years of age). ${ }^{15}$ Vascular malformations show slow growth throughout life with increase in response to infection, trauma, or hormonal fluctuation and they do not involute. ${ }^{16,17}$ Osseous involvement of the hemangiomas is rare but $35 \%$ of the vascular malformations show osseous involvement. ${ }^{18}$
Although most hemangiomas of the tongue are asymptomatic, they could sometimes cause significant bleeding, pain or difficulty in chewing, speaking, and even swallowing, if they are large enough. Small lesions can be excised. Large lesions, if excised, could result in significant functional disability. This is why several modalities of less invasive treatment have recently been advocated (Argon laser, Nd: YAG laser, or both to avoid functional disability caused by tissue loss). Also, there have been reports of treatment with super selective embolization using polyvinyl alcohol foam (Ivalon) and absorbable gelatin sponge (Gelfoam) particulates.

Although hemangiomas are common in infancy and childhood, they are probably developmental abnormalities rather than true neoplasms. Pathologists distinguish three classes: capillary, cavernous, and mixed types. Cavernous hemangiomas are blue, soft, spongy masses that are not encapsulated. Some hemangiomas of the tongue have a lymphangiomatous component, hence the name hemangiolymphangiomas.

\section{INVESTIGATIONS}

UItrasonography and color Doppler examination are inexpensive and non-invasive imaging techniques and are used most commonly to confirm the diagnosis. ${ }^{19-21}$ Grey-scale ultrasound and Doppler analysis are a useful in determining whether the lesion is solid or cystic and to establish the presence or absence of high flow vessels. Sonography has been advocated as useful in examining soft-tissue masses that are suggestive of hemangiomas or vascular malformations. ${ }^{19,20}$ Vessel density as depicted on Doppler sonography has been used in differentiating other types of masses from vascular malformation. ${ }^{21}$ Certainly, the Doppler characteristics of vascular malformations are hel pful in differentiating low-from high-flow vascular malformations. ${ }^{22}$

\section{Result}

Reconstruction of a medium-sized defect of the tongue remains a challenge if functional and aesthetic impairment is to be avoided. The tongue base island advancement flaps developed to reconstruct medium-sized defect. The size amounts to $4.5 \times 3 \mathrm{~cm}$ (length $\times$ width). The tongue base island 
advancement flap reduces the volume of the tongue base without causing function impairment of the tongue. The patient recovered with good objective and subjective speech, swallowing and aesthetics. Patient has no local recurrence. The technique of tongue baseadvancement flap is ideal for functional and aesthetic repair of medium-sized tongue defects.

\section{CONCLUSION}

A variety of methods of treatment are thus available for intraoral hemangiomas. The majority of these lesions can be regarded as capillarycavernous hemangiomas. While surgical removal of oral hemangiomas is indicated for small lesions its use with large lesions lead to extensive tissue defect and rapid bleeding which might be difficult to control. Cryosurgery, on the other hand, is very effective in small superficial lesions but is completely ineffective in large deep ones. E mbolization, utilizing various materials, is used to obstruct the vessels, with excellent results but requires considerable expertise from the technical point of view and serious complications such as tearing the vessels and over dilatation might occur. Circumferential excision and rotational advancement flap is therefore a valuable technique requiring minimal experience while aiming at achieving normal functional and aesthetic repair of medium-sized tongue defects.

\section{References:}

1. Mulliken J B, Glowacki J. Hemangiomas and vascular malformation in infants and children: A classification based on endothelial characteristics. Plast Reconstr Surg 1982; 69:412-422.

2. Kaban LB, Mulliken J B. Vascular anomalies of the maxillofacial region. Oral Maxill ofac Surg 1986; 44:203-213.

3. Fishman SJ, Mulliken J B. Hemangiomas and vascular malformations of infancy and childhood. Pediatr Clin N orth Am 1993; 40:1177-1200.

4. Fishman SJ, Burrows PE, Leichtner AM, Mulliken J B. Gastrointestinal manifestations of vascular anomalies in childhood: varied etiologies require multiple therapeutic modalities. J Pediatr Surg 1998; 33:1163-1167.

5. Apfel berg DP. Treatment of hemangiomas. In: Georgiade GS: Textbook of plastic, maxillofacial and reconstructive surgery. Williams \& Wilkins, 1992:223-229.

6. Finn MC, Glowacki J, Mulliken J B. Congenital vascular lesions: clinical application of a new classification. J Pediatr Surg 1983; 18:894-900.

7. Dieterich-Miller CA, Safford PL. Psychosocial development of children with hemangiomas: home, school, health care collaboration. Child Health Care 1992; 21:84-89.
8. Kunkel EJ, Zager RP, Hausman CL, Rabinowitz LG. An interdisciplinary group for parents of children with hemangiomas. Psychosomatics 1994; 35:524-532.

9. Enjolras O, Riche MD, Merland JJ, Escande JP. Management of alarming hemangiomas in infancy: a review of 25 cases. Pediatrics 1990; 85:491-498.

10. Waner M, Suen JY. Hemangiomas and vascular malformations of the head and neck. New York: Wiley-Liss; 1999.

11. Williams III EF, Stanislaw P, Dupree M, Mourtzikos K, Mihm M, Shannon L. Hemangiomas in infants and children: an algorithm for intervention. Arch Facial Plast Surg 2000; 2:103-111.

12. Troilius A, Wrangsjo B, Ljunggren B. Potential psychological benefits from early treatment of portwine stain in children. Br J Dermatol 1998; 139:59-65.

13. Miller AC, Pit-Ten Cate IM, Watson HS, Geronemus RG. Stress and family satisfaction in parents of children with facial port-wine stains. Pediatr Dermatol 1999; 16:190-197.

14. M. Ethunandan, Timothy K. Mellor. Haemangiomas and vascular malformations of the maxillofacial region-A review. British J ournal of Oral and Maxillofacial Surgery 2006; 44:263-272.

15. Takahashi K, Mulliken J B, Kozakewich HP, Rogers RA, Folkman J, Ezekowitz RA. Cellular markers that distinguish the phases of hemangioma during infancy and childhood. J Clin Invest 1994; 93:2357-2364.

16. Clymer MA, Fortune DS, Reinisch L, et al. Interstitial Nd: YAG photocoagulation for vascular malformations and hemangiomas in childhood. Arch Otolaryngol Head Neck Surg. 1998; 124:431-436.

17. J ohann AC, Salla J T, Gomez RS, de Aguiar MC, Gontijo B, Mesquita RA. GLUT-1 in oral benign vascular lesions. Oral Dis. J an 2007; 13(1):51-57.

18. Williams TP, Stewart JCB, FONSECA, Oral and Maxillofacial Surgery, volume 5, surgical pathology, chapter 15, Peter E Larsen, pg:432-445.

19. Paltiel HL, Burrows PE, Mulliken J B. Color Doppler ultrasound of soft tissue vascular anomalies. Radiology 1994; 193:292-295.

20. Dubois J , Garel L, Gignon A, Laberge L, Filiatrault D, Powell J. I maging of hemangiomas and vascular malformations in children. Acad Radiol 1998; 5:390-400.

21. Dubois J, Patriquin HB, Garel L, et al. Soft-tissue hemangiomas in infants and children: diagnosis using Doppler sonography. AJ R 1998; 171: 247-252.

22. Donnelly LF, Bisset GS III, Adams DM. Combined sonographic and fluoroscopic guidance: a modified technique for percutaneous sclerosis of low-flow vascular malformations. AJ R 1999; 173:655-657. 